\title{
Article \\ Keeping a Clean Surface under Water: Nanoscale Nipple Array Decreases Surface Adsorption and Adhesion Forces
}

\author{
Kaoru Uesugi ${ }^{1}$, Kazuaki Nagayama ${ }^{1}$ and Euichi Hirose ${ }^{2, *(D)}$ \\ 1 Department of Mechanical Systems Engineering, Graduate School of Science and Engineering, \\ Ibaraki University, Hitachi 316-8511, Japan; kaoru.uesugi.biomech@vc.ibaraki.ac.jp (K.U.); \\ kazuaki.nagayama.bio@vc.ibaraki.ac.jp (K.N.) \\ 2 Department of Chemistry, Biology and Marine Science, Faculty of Science, University of the Ryukyus, \\ Okinawa 903-0213, Japan \\ * Correspondence: euichi@sci.u-ryukyu.ac.jp
}

check for updates

Citation: Uesugi, K.; Nagayama, K. Hirose, E. Keeping a Clean Surface under Water: Nanoscale Nipple Array Decreases Surface Adsorption and Adhesion Forces. J. Mar. Sci. Eng. 2022, 10, 81. https://doi.org/ 10.3390/jmse10010081

Academic Editor: Nick Aldred

Received: 22 November 2021

Accepted: 5 January 2022

Published: 8 January 2022

Publisher's Note: MDPI stays neutral with regard to jurisdictional claims in published maps and institutional affiliations.

Copyright: (C) 2022 by the authors. Licensee MDPI, Basel, Switzerland. This article is an open access article distributed under the terms and conditions of the Creative Commons Attribution (CC BY) license (https:// creativecommons.org/licenses/by/ $4.0 /)$.

\begin{abstract}
While nanoscale nipple arrays are expected to reduce light reflection and/or dust contamination in some insects, similar structures have been reported in various marine invertebrates. To evaluate the anti-contamination property of the structure in aquatic regimes, we measured the adsorption and adhesion forces on the flat surface and MOSMITE ${ }^{\mathrm{TM}}$ (Mitsubishi Chemical Corporation, Tokyo, Japan), a synthetic material mimicking the nipple array, under water. A small force toward the surface occurred when the probe approached the substrate surface. This adsorption force was significantly smaller on MOSMITE ${ }^{\mathrm{TM}}$ than on the flat surface. The adhesion force toward the surface occurred when the probe was detached from the surface, and it was also significantly smaller on MOSMITETM $^{\mathrm{TM}}$ than on the flat surface. The adhesion force in the air was much greater than the force under water, and the force was also significantly smaller on MOSMITETM than on the flat surface. In the aquatic regime, the nipple array provides less adsorption/adhesion properties for the surface and thus, the organisms would have less contamination of microparticles on their body surface. As the adsorption and adhesion forces are also involved in the attachment of cells, tissue, and larvae, less adhesive body surfaces should be beneficial for survival in aquatic environments, as well as land environments.
\end{abstract}

Keywords: adhesion force; adsorption force; anti-contamination; aquatic regime; Atomic Force Microscope (AFM); colloidal probe; moth-eye structure; MOSMITETM

\section{Introduction}

Some microscopic structures of biological surfaces are known to provide amazing functions for various organisms, such as self-cleaning [1], water capture [2], reduction in fluid friction [3], and super-hydrophobicity for floating on the water surface [4,5]. These structures and functions have attracted attention as resources for biomimetic applications. Nanoscale nipple arrays (or "moth-eye structures") were originally reported from the cornea of the compound eyes of a night moth [6] and this surface structure forms a gradient of refractivity, resulting in the reduction in light reflection and the increase in light transmittance [6,7]. This structure can be regarded as a multifunctional structure; the nipple array on the cicada wing and the cornea of some insects was shown to reduce adhesion and water wettability and may serve anti-contamination and anti-wetting purposes, respectively [8,9]. Furthermore, Ivanova et al. [10,11] proposed the bactericidal properties of the nipple array. Nanoscale nipple arrays and similar structures have been found in terrestrial insects as well as various invertebrate taxa inhabiting aquatic environments, such as annelids, echinoderms, sessile and pelagic tunicates, and endoparasitic copepods [12-19]. The convergent evolution of similar structures may imply their functional importance in the survival of organisms. However, the major functions of the structure may not always be the same among organisms as the structures occur in organisms of various sizes, life 
histories, and habitats. However, there are few studies on the potential functions of nipple arrays in aquatic environments. The simulation, based on the rigorous coupled wave analysis, supported the assertion that the nipple array reduces surface reflectance under water, but the reduction effect is estimated to be much smaller than that in terrestrial environments because of the smaller difference in refractive indices between water and the body surface $[20,21]$.

The following potential underwater functions were evaluated using synthetic materials, i.e., nanopillar sheets and MOSMITE ${ }^{\mathrm{TM}}$ (Mitsubishi Chemical Corporation, Tokyo, Japan), as a mimetic model for nipple arrays compared to a flat surface made of the same material: the inhibition of bubble attachment [22]; the suppression of cell spreading and phagocytic activity [23]; and the reduction in larval settlements [23,24]. The results suggest that the nipple array is less adhesive than a flat surface. Aquatic organisms are exposed to fine mud grains and other microscale particles that are usually suspended in water, and the adhesion of these particles may reduce the structural and chemical functions of the body surface. Therefore, a reduction in surface adhesiveness would be beneficial for aquatic organisms. Under atmospheric conditions, the measurement of the adhesion force using Atomic Force Microscopy (AFM) demonstrated that nanoscale nipple arrays reduce surface adhesiveness [8,9]. In the measurements in the aerobic regime, a thin water film is supposed to exist between the substrate surface and the AFM probe and the water film forms a meniscus that generates a large adhesion force owing to the surface tension. On the other hand, the adhesion force on the surface under water is expected to be much smaller than that under atmospheric conditions because the meniscus is not formed in the aquatic regime. Therefore, it is necessary to measure the adhesion force on the nipple array structure in aquatic conditions to elucidate the biological functions of this nanostructure. In the present study, we measured the surface adhesiveness of MOSMITE ${ }^{\mathrm{TM}}$ and the flat film under water using AFM with a $\mathrm{SiO}_{2}$ colloidal probe, assuming a clay particle. The present study aimed to clarify whether the nanoscale nipple array adheres less to microparticles than a flat surface under water as is known to happen in the air. Additionally, by using a cone probe, we also confirmed that the surface structures of MOSMITE ${ }^{\mathrm{TM}}$ are the same underwater as under atmospheric conditions.

\section{Materials and Methods}

\subsection{Materials}

$\operatorname{MOSMITE}^{\mathrm{TM}}$ (E075M2N) and flat film were generously provided by Mitsubishi Chemical Corporation (Tokyo, Japan). In these films, acrylic resin was coated onto the base films of polyethylene terephthalate to form nanostructures. One side of MOSMITE ${ }^{\mathrm{TM}}$ film has a 'moth-eye structure' that is a nipple array about $100 \mathrm{~nm}$ in height, while there were no structures on the flat film (Figure 1). The other side of the film was covered with a layer of adhesives. The MOSMITETM films and flat films were cut into approximately $5 \mathrm{~mm}$ squares. To calibrate the AFM probe in the same environment with geometrical observation and adhesion force measurement, a pair of MOSMITE ${ }^{\mathrm{TM}}$ and flat films was pasted on a glass-bottom dish, $60 \mathrm{~mm}$ in diameter (P60G-1.5-30-F, MatTek Co., Ashland, MA, USA). The dish was filled with distilled water for the underwater measurement.

\subsection{AFM Measurement of Surface Structure}

The geometrical properties of the MOSMITE ${ }^{\mathrm{TM}}$ were examined using AFM (NanoWizard IV AFM, Bruker Nano GmbH, Berlin, Germany). The AFM was mounted on top of an inverted optical microscope (IX73, Olympus, Japan), equipped with a digital CMOS camera (Zyla, Andor Technology Ltd., Belfast, UK). We applied the AFM quantitative imaging (QI) mode [25] and obtained a force-displacement curve at each pixel of $128 \times 128$ pixels $(1 \times 1 \mu \mathrm{m}$ of measured area). A precisely controlled contact scanning test was employed with triangular silicon nitride cantilevers and a cone probe (DNP-10 (cantilever C), Bruker Co., Billerica, MA, USA) at a pre-calibrated spring constant $(0.321 \mathrm{~N} / \mathrm{m}$ in the air and $0.349 \mathrm{~N} / \mathrm{m}$ under water) and a nominal tip radius of $20 \mathrm{~nm}$ (typical value). 

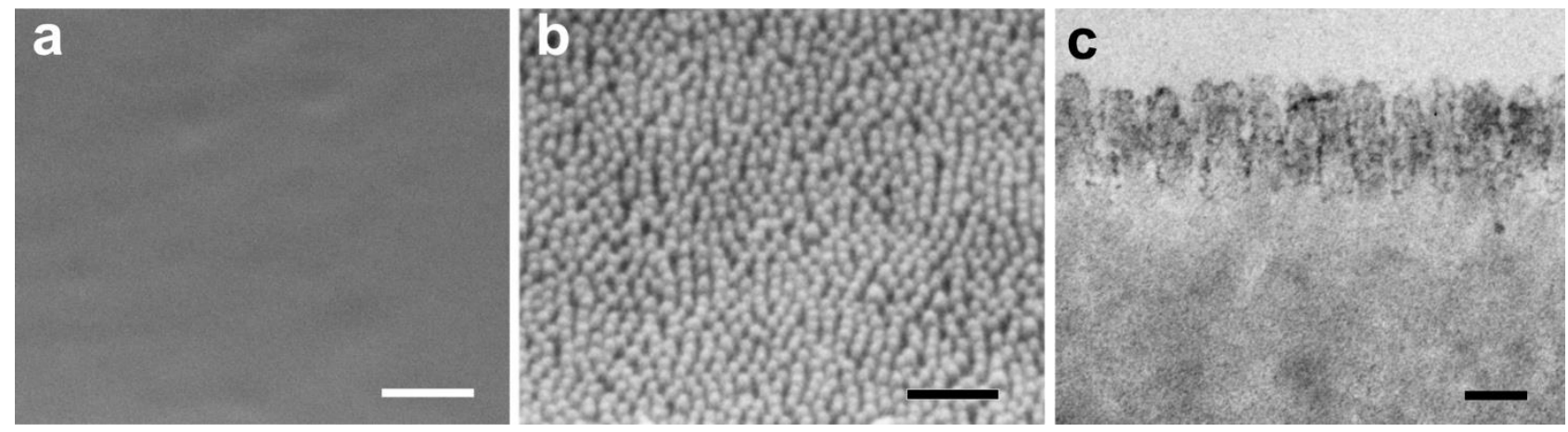

Figure 1. Ultrastructure of the film surface in scanning electron microscopy (SEM: $(\mathbf{a}, \mathbf{b})$ ) and transmission electron microscopy (TEM: (c)). (a), flat film; (b,c), MOSMITE ${ }^{\mathrm{TM}}$. Scale bars: $0.5 \mu \mathrm{m}$ in (a,b); $0.1 \mu \mathrm{m}$ in $(\mathbf{c})$.

The scanning observations were carried out in the air and then carried out under water. Prior to scanning, the probe was dehydrated and decontaminated by plasma exposure (atmospheric pressure, $10 \mathrm{~Pa}$; current, $5 \mathrm{~mA}$; exposure time, $2 \mathrm{~min} \times 3$ times) with soft plasma etching equipment (SEDE-GE, Meiwafosis Co., Ltd., Tokyo, Japan). Before the force measurement in the air, the static electricity of the sample was eliminated using a fan-type ionizer (KD-750B-1, Kasuga Denki, Ink., Kawasaki, Japan). In the scanning tests, each indentation of the probe was performed until the indentation force reached $3 \mathrm{nN}$. The obtained force curves were integrated into the AFM images and the profiles of the cross sections using the data processing software (JPK Data Processing Version spm-6.1.110, Bruker Nano GmbH, Berlin, Germany). Due to the high aspect ratio of the nipples and the short pitch between the nipples, the tip of the probe did not reach the bottom of the nipple array. Therefore, the measured values were reliable for the pitch and apical shape of the nipples, but not for the height of the nipples.

\subsection{AFM Measurement of Adsorption and Adhesion Force}

The same AFM system was employed for the measurements to compare the forces on the MOSMITE ${ }^{\mathrm{TM}}$ and flat surfaces. We applied the AFM contact mode and obtained a force-displacement curve at each pixel of $8 \times 8$ pixels $(1 \times 1 \mu \mathrm{m}$ of measured area). A rectangular silicon nitride cantilever with a colloidal probe $(4-\mu \mathrm{m}$ diameter) attached by the manufacture (SD-Sphere-CONT-L, NanoWorld-AG, Neuchâtel, Switzerland) was used for the measurements. The pre-calibrated spring constants were $0.206 \mathrm{~N} / \mathrm{m}$ in the air and $0.216 \mathrm{~N} / \mathrm{m}$ under water. In this study, we aimed to estimate the adhesion force between a particle of clay drifting in a water column and the marine organisms, with or without nipple array structures, and we used a 4- $\mu \mathrm{m}$ sphere colloidal probe whose surface material was $\mathrm{SiO}_{2}$, due to the following reasons. Clay is generally composed of two basic components, a silica tetrahedral sheet and an aluminum octahedron sheet $[26,27]$, and $\mathrm{SiO}_{2}$ is one of the main theoretical components of clay without interlayer materials. The diameter of clay is defined as less than $5 \mu \mathrm{m}$ [28].

As with the measurement of the surface structures, the force measurements were carried out in the air and then carried out under water. Prior to the measurements, the probe was dehydrated and decontaminated by plasma exposure. Before the force measurement in the air, the static electricity of the sample was eliminated using an ionizer in the air. In the measurements, each indentation of the probe was performed until the indentation force reached $20 \mathrm{nN}$. The range of the vertical movement of the cantilever was $1 \mu \mathrm{m}$, and each indentation was carried out at a speed of $0.2 \mu \mathrm{m} / \mathrm{s}$. The force measurement comprised two phases: extension and retraction. At the beginning of the measurement, the probe was fully separated from the sample (a flat film or MOSMITE ${ }^{\mathrm{TM}}$ ). The force applied on the probe was measured as the vertical deflection and the value was zero at this original position. In the extension phase, the probe was extended toward the substrate surface until the distance between the probe and the surface reached zero and the probe was slightly pushed against 
the surface. The probe was then retracted to its original position in the retraction phase. The data were analyzed using data processing software to obtain the force curves.

\subsection{Statistics}

The measured values under water and in the air or on MOSMITETM and the flat film were compared using the Student $t$-test or Mann-Whitney $U$-test, following the ShapiroWilk test for normality and F-test for equal variances, in R version 3.5.1 (RRID:SCR_001905) and RStudio (RRID:SCR_000432).

\section{Results}

\subsection{Surface Structure}

The AFM images of the MOSMITE ${ }^{\mathrm{TM}}$ surface measured under water and in the air were similar to each other (Figure 2a,b). The pitches of the measured nipples were $82.8 \pm 28.3 \mathrm{~nm}$ (average $\pm \mathrm{SD}, N=10$ ) under water and $92.9 \pm 16.8 \mathrm{~nm}(N=9)$ in the air (Figure 2c,d). Significant difference was not supported between them (Student $t$-test, $p=0.365$ ). The heights under water $(22.6 \pm 10.9 \mathrm{~nm}, N=11)$ were significantly greater than those in air $(12.9 \pm 5.0 \mathrm{~nm}, N=10)$ (Mann-Whitney $U$-test, $p<0.05)$ (Figure $2 \mathrm{c}, \mathrm{d}$ ), but the values of the height measurements were not reliable as explained in the method section. The noise (deformations of the baseline of the force curves) caused by static electricity was occasionally observed in the measurements in the air.
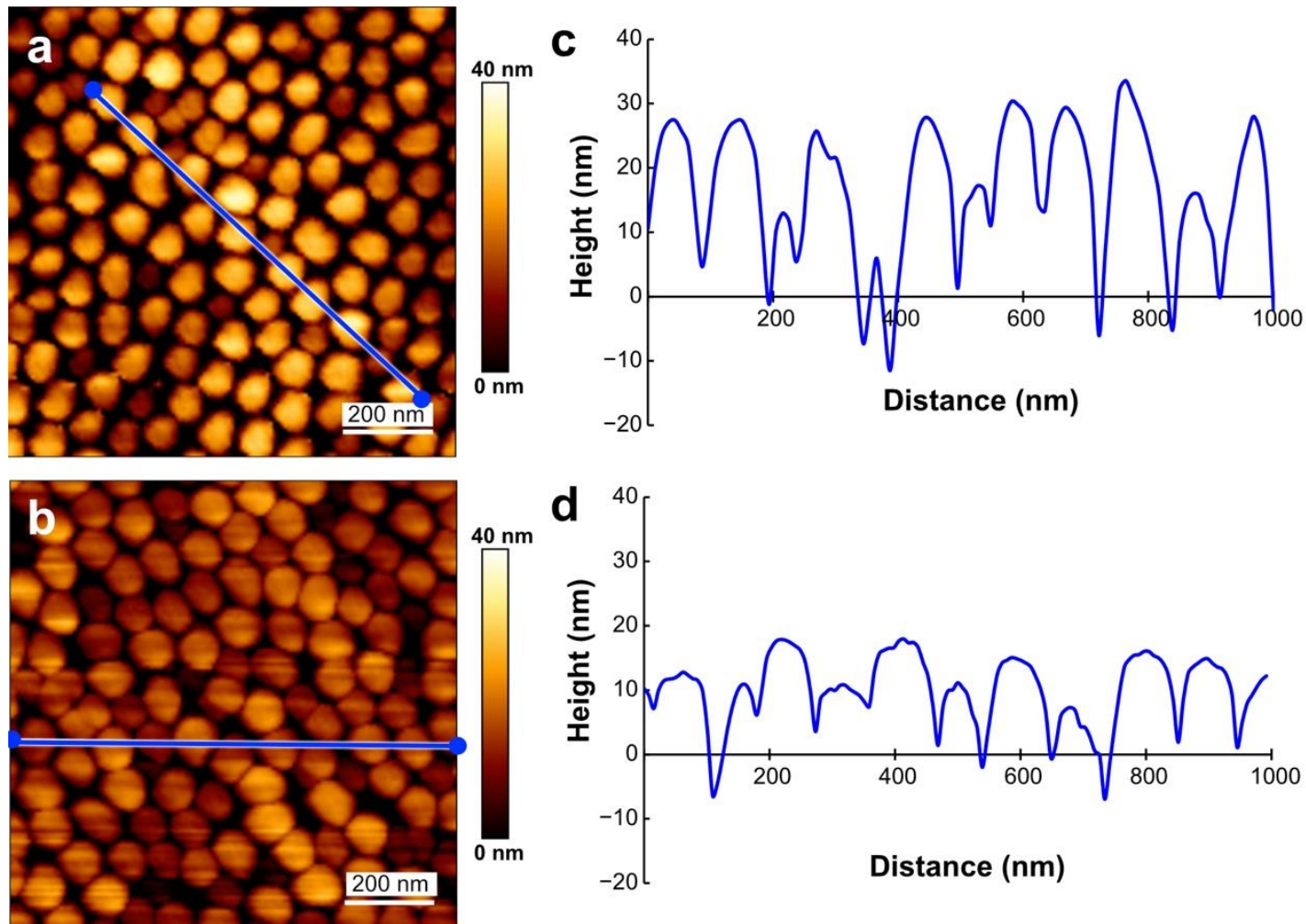

Figure 2. AFM images of the MOSMITE ${ }^{\mathrm{TM}}$ surface under water $(\mathbf{a}, \mathbf{c})$ and in the air $(\mathbf{b}, \mathbf{d})$. The profiles $(\mathbf{c}, \mathbf{d})$ are the cross sections along the blue lines in $(\mathbf{a}, \mathbf{b})$, respectively.

\subsection{Adsorption and Adhesion Force}

Figure 3 shows a case of the measurement on the flat surface (a) and on the MOSMITE ${ }^{\mathrm{TM}}$ (b) under water. In the graphs, the extension phase begins at the right end of the graph and moves leftward, and the value of the vertical deflection rises sharply when the probe touches and presses the substrate (blue line). The retraction phase begins at the left end (distance $=0)$, where the probe presses the substrate and moves rightward (red line). 

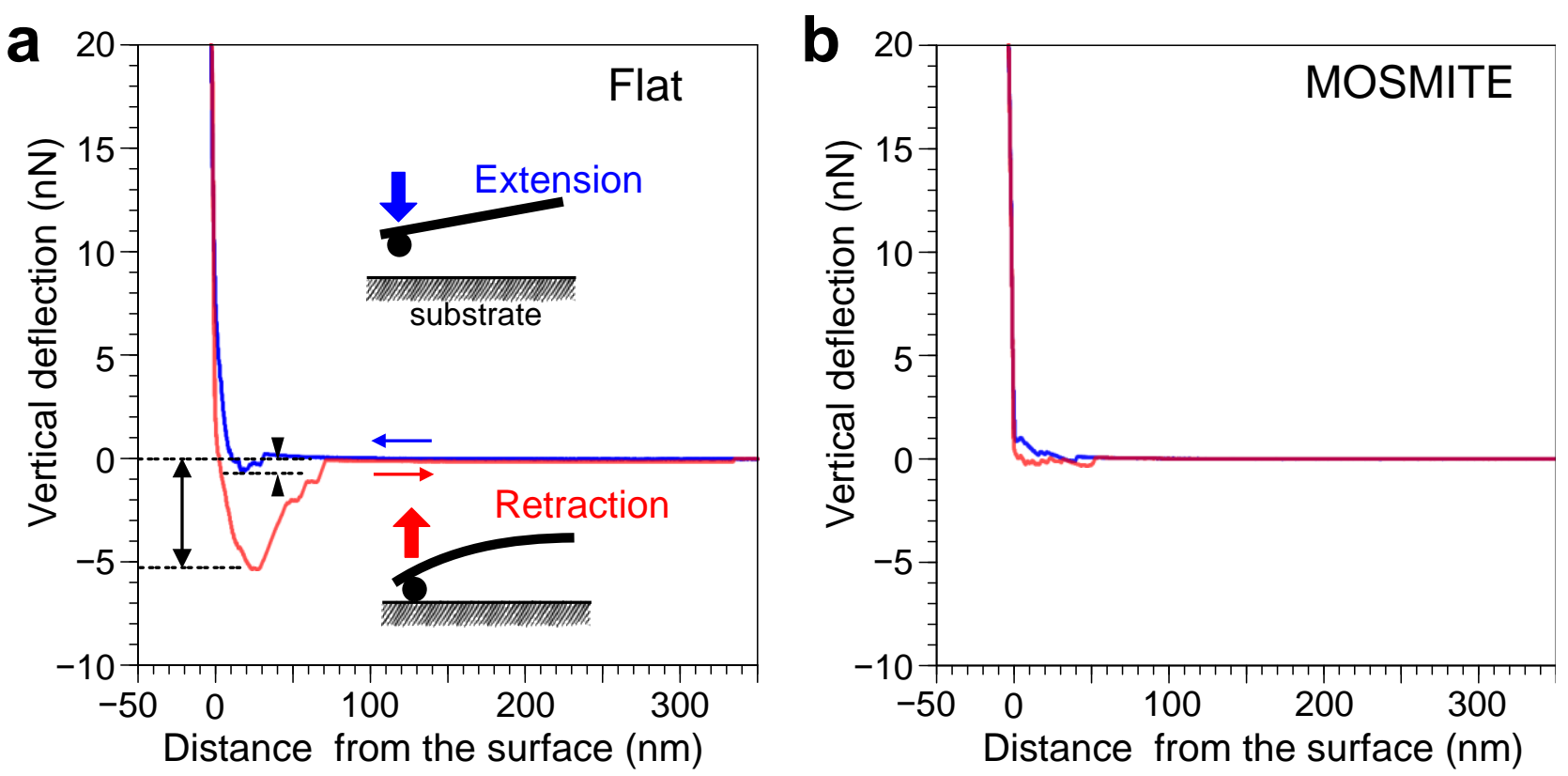

Figure 3. Measurement of adsorption force and adhesive force on the flat surface (a) and MOSMITE ${ }^{\mathrm{TM}}$ surface (b) under water. The probe was extended toward the film surface (blue lines), slightly pressed on the film, and then retracted (red lines). When the probe just touched the surface, the distance from the surface was zero. The arrowheads indicate the adsorption force. The two-way arrow indicates the adhesion force on the surface.

In the extension phase of the measurement under water, the force curve shows jump-in behavior when the probe approached the flat surface. This force applied on the probe toward the surface was called the adsorption force in this study. In Figure 3a, the adsorption force occurred within approximately $30 \mathrm{~nm}$ of the surface and was $0.6 \mathrm{nN}$ at the maximum; these values were slightly variable among the measurements. The forces were small or undetectable on MOSMITETM (Figure 3b). In 64 measurements for each of the substrates under water, the adsorption force was $0.91 \pm 0.33 \mathrm{nN}$ (average \pm standard deviation) on the flat surface and $0.20 \pm 0.15 \mathrm{nN}$ on the MOSMITE ${ }^{\mathrm{TM}}$. The adsorption force on the flat surface was significantly greater than that on the MOSMITE ${ }^{\mathrm{TM}}$ (Mann-Whitney $U$-test, $p<0.001$ ) (Figure 4a). Besides the adsorption force, in some measurements, small repulsive forces were recorded just before the probe snapped onto the surface during the extension phase (Figure 3). The considerable noise due to static electricity made it impossible to measure the adsorption force in the air reliably.

In the retraction phase of the measurement under water, the force toward the surface was applied to the probe when the probe was detached from the surface (Figure 3). This force was called adhesion force in this study. Under water, the adhesion force was $3.9 \pm 0.33 \mathrm{nN}$ (average \pm standard deviation, $N=64$ ) on the flat surface and $1.0 \pm 0.26 \mathrm{nN}$ $(N=61)$ on the MOSMITE ${ }^{\mathrm{TM}}$. In the air, the adhesion force was much larger than the force under water: $105 \pm 31 \mathrm{nN}$ (average \pm standard deviation, $N=58$ ) on the flat surface and $13 \pm 4.6 \mathrm{nN}(N=64)$ on the MOSMITE ${ }^{\mathrm{TM}}$. The adhesion force on the flat surface was significantly greater than that on the MOSMITE ${ }^{\mathrm{TM}}$ under water (Mann-Whitney $U$-test, $p<0.001$ ) (Figure $4 b$ ) as well as in the air (Mann-Whitney $U$-test, $p<0.001$ ) (Figure $4 c$ ). 

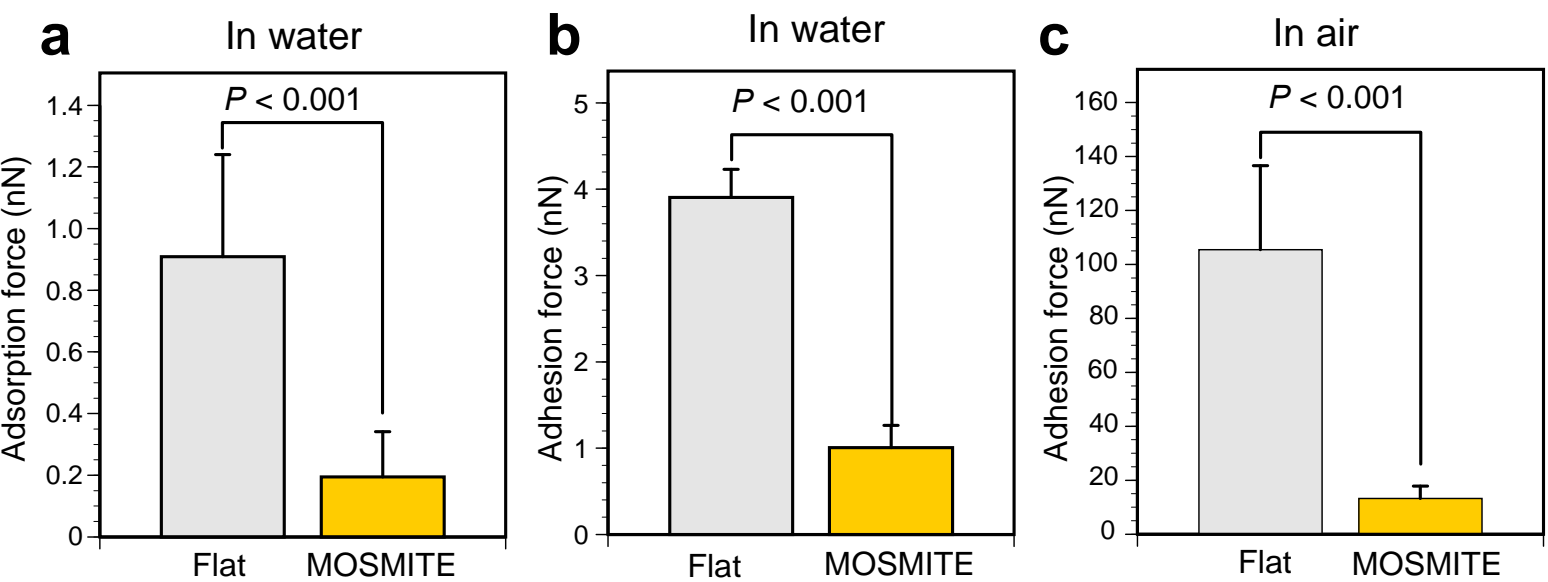

Figure 4. Comparison of the adsorption force and adhesion force on the flat surface and the MOSMITE ${ }^{\mathrm{TM}}$ surface. (a), Adsorption force under water. (b), Adhesion force under water. (c), Adhesion force in the air. Significant differences were tested using the Mann-Whitney $U$-test.

\section{Discussion}

Underwater AFM measurements with a cone probe with a 20-nm tip confirmed the size and shape of the nanoscale nipple array of the MOSMITE ${ }^{\mathrm{TM}}$ in the air. Measurements with the colloidal probe under water also showed that the MOSMITE ${ }^{\mathrm{TM}}$ adsorbs less and adheres less to the microparticles than the flat film, indicating the anti-contamination property of the nipple array in the aquatic regime, as reported in the aerobic regime. In addition, the surface properties of the MOSMITE ${ }^{\mathrm{TM}}$ under water may expand the potential applications of this biomimetic material that can be mass produced.

In the AFM images obtained under atmospheric and aquatic conditions, the shapes of the apical parts of the nipples on the MOSMITE ${ }^{\mathrm{TM}}$ were similar to each other (Figure 2a,b) and were consistent with the scanning and transmission electron micrographs of the MOSMITE $^{\mathrm{TM}}$ (Figure 1b,c). The pitch of the nipples was almost the same as the pitch in the electron micrographs. Therefore, it is considered that the nipple-like structures were not deformed, swollen, or shirked under water. The height of the structure was much shorter in the AFM measurements (Figure $2 c, d$ ) than in the electron micrographs (Figure $1 b, c$ ) because the probe tip did not reach the bottom of the nipple array due to the high aspect ratio of the structure. Moreover, the measured height in the air was shorter than that under water, likely due to electrostatic interference in the measurements.

In AFM measurements with a $4-\mu \mathrm{m}$ diameter colloidal probe under water, a small force toward the surface was exerted on the probe when the probe came within several dozen nanometers of the substrate surface. Accordingly, the microparticle approaching the surface would be pulled and attached to the surface by this force, which was assigned as the adsorption force. While the force was only approximately $1 \mathrm{nN}$ on the flat surface, it may facilitate the attachment of the particles. On the MOSMITE ${ }^{\mathrm{TM}}$, the adsorption force was significantly smaller than the force on the flat surface (Figure 4a), indicating that the nipple array suppresses the adsorption of the particles on the surface in the aquatic regime. The adsorption force recorded in our measurements was so small that we could not measure the force in the air due to fluctuations in the measured values caused by electrostatic interference. A small repulsion force was also recorded in some underwater measurements, suggesting that a small electrostatic repulsion may occur even in the aquatic regime. This small force was overcome by a larger adsorption force that snapped the probe onto the surface.

When the colloidal probe was detached from the flat surface, a force toward the surface was exerted on the probe. This force was assigned as an adhesion force that would operate on the particle to fix it onto the surface. On the MOSMITE ${ }^{\mathrm{TM}}$, the adhesion force was significantly smaller than the force on the flat surface (Figure $4 \mathrm{~b}$ ), indicating that the nipple array facilitates the detachment of the particles from the surfaces in the aquatic regime. The 
adhesion force was much greater in the measurements in the air, likely because the surface tension of the water meniscus formed between the particle and the surface generates an adhesion force in the aerobic regime but not in the aquatic regime. In the air, the force on the flat surface was significantly greater than the force on the MOSMITETM (Figure 4c), as reported in previous studies in which the colloidal probes were different in size from the probe used in the present study [8,9]. On the immobilized nanoparticles $(26,44,53,98$, and $152 \mathrm{~nm}$ in diameter), the adhesion force between the nanoparticles and the probe coated with Escherichia coli cells was the smallest on the 98-nm particles, and the size effects on the adhesion forces was considered to be due to the difference in local effective contact area [29]. Whereas the values of the adhesion force would be variable depending on the particle size, material hardness, and other parameters, it may be interesting that the nipple array approximately $100 \mathrm{~nm}$ high is common in both terrestrial and aquatic invertebrates, such as the lepidopterans [30] and the ascidians [16]. The shape of the nipples is also linked with their functional properties. Several patterns and various transitions have been described in the corneal nanostructures in insects [31], and partially merged protrusions are less adhesive and more reflective than individual protrusions in the corneal nipple array of fruit flies Drosophila spp. [32].

The adhesion force in the aquatic regime $(\approx 4 \mathrm{nN}$ on the flat surface, $\approx 1 \mathrm{nN}$ on MOSMITE $\left.{ }^{\mathrm{TM}}\right)$ was much smaller than the force in the aerobic regime $(\approx 105 \mathrm{nN}$ on the flat surface, $\approx 13 \mathrm{nN}$ on MOSMITE $\left.{ }^{\mathrm{TM}}\right)$, and the adsorption force $(\approx 1 \mathrm{nN}$ on the flat surface, $\approx 0.2 \mathrm{nN}$ on MOSMITE ${ }^{\mathrm{TM}}$ ) was even smaller than the adhesion force. However, these forces are much more effective for particle attachment than relative gravity. Here, we propose a simple mechanical model of the forces that are exerted on a clay particle close to the surface. Kaolinite is one of the most common clay minerals in sedimentary and residual soils, and its relative density to water is about $2.6 \mathrm{Mg} / \mathrm{m}^{3}$ [26] while the relative density of water and surface seawater is 1 and 1.02-1.03, respectively. Accordingly, the relative gravity force exerted on a kaolinite sphere with a $4 \mu \mathrm{m}$ diameter is estimated to be about $0.53 \mathrm{pN}$ in water and $0.52 \mathrm{pN}$ in seawater. As the relative gravity force is negligibly small, reducing the adhesion and adsorption forces on the nanoscale nipple array is expected to be effective for anti-contamination. The forces lodging a sphere with a diameter of $4 \mu \mathrm{m}$ are summarized in Figure 5, with approximate estimates of the values.

\section{a Close to the surfaces}

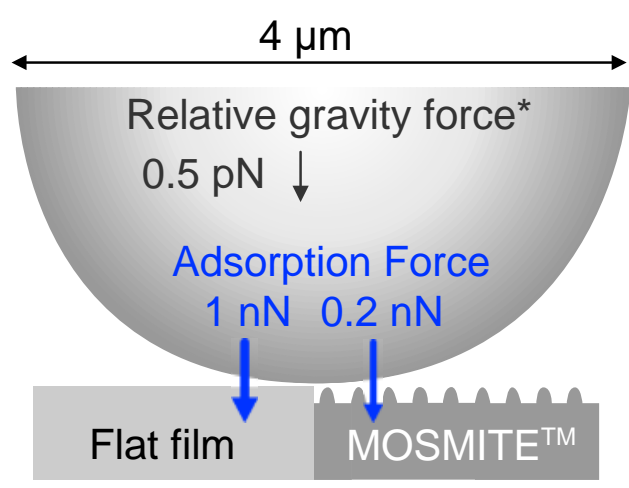

\section{b On the surfaces}

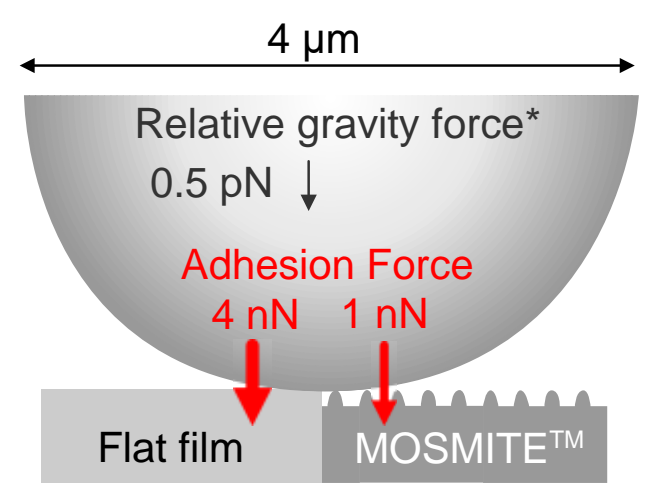

Figure 5. Summary of the forces lodging a 4- $\mu \mathrm{m}$ particle. An approximate value is shown for each force. (a), A sphere coming close to the surface of the flat film and MOSMITE ${ }^{\mathrm{TM}}$. (b), A sphere adhering to the surfaces. *, Values for kaolinite.

Fluid friction is known to be reduced on the surface of microstructures [33] and the friction reduction effect on water flow may be another possible function of the nipple array that needs to be considered. This effect may synergistically facilitate anti-contamination by reducing adsorption and adhesion forces. The flow velocity is generally attenuated by the friction resistance near a smooth solid surface (moderate velocity gradient near the surface). 
On the other hand, the flow near the nipple array will be less attenuated than the flow near the flat surface (rapid velocity gradient near the surface) owing to the mixed effect of turbulence flow. As the drag force on the object becomes greater in a faster flow, particles on the nipple array will be carried away from the surface more easily than particles on the flat surface. Hydrodynamic analyses are required to evaluate this possibility. In the present study, we could not conclude which process, such as the reduction in effective contact area and reduction in the flow attenuation, predominantly causes the lower adhesion on the nipple array than the flat surface.

The use of synthetic materials enabled us to compare the difference in adhesion between the same material with and without the nanostructure. However, we cannot ignore the fact that the MOSMITE ${ }^{\mathrm{TM}}$, made of acrylic resin and a biological surface, would have different chemical properties because the chemical interaction between materials is also important for adhesion. It is necessary to measure the adhesion force of the biological body surfaces of live specimens in a future study.

\section{Conclusions}

The present study indicated that the nanoscale nipple array provides less adsorption and less adhesion to the surface in the aquatic regime and thus, the organisms with the nipple array would be less contaminated with microparticles on their body surface than would those with a flat surface. Whereas the forces exerted on the particle under water are much smaller than are those in the air, the particles floating in water are much greater in number, size, and variation than the particles suspended in the air. Therefore, the substantial role of anti-contamination would be different in aquatic and terrestrial organisms. The contamination of the body surface may reduce its structural and chemical functions. In addition to mud grains, the particles under water include microbial and organic materials that form a primary biofilm on the surface. A biofilm changes the properties of the surface, such as wettability [34], and mask the nanostructures on the surface and thus, the control of the formation and reduction in the primary biofilm would be a pivotal key to biofouling and the success of the community [35]. Adsorption and adhesion forces are also involved in the attachment of cells, tissue, and larvae; the nipple arrays on the body surfaces may reduce infections from parasites and fouling on the body $[24,36]$ and may mitigate cellular attacks from the host organisms in parasitic animals [23]. Therefore, less adhesive body surfaces served by the nanoscale nipple array should be beneficial for aquatic organisms as well as terrestrial organisms. This anti-adhesive property under water also indicates that the MOSMITE ${ }^{\mathrm{TM}}$ film could be used as an underwater antifouling material.

Author Contributions: E.H. designed the study. K.U. and K.N. performed the measurements. K.U. and E.H. drafted the manuscript. All authors have read and agreed to the published version of the manuscript.

Funding: The present study was partly supported by KAKENHI (No. 21K06252) from the Japan Society for the Promotion of Science, granted to K.U. and E.H.

Institutional Review Board Statement: Not applicable.

Informed Consent Statement: Not applicable.

Data Availability Statement: The datasets supporting the conclusions of this article are included within the article.

Acknowledgments: We thank Yoshihiro Uozu and Yuusuke Nakai (Mitsubishi Chemical Corporation) for generously providing the MOSMITE ${ }^{\mathrm{TM}}$ and the flat film.

Conflicts of Interest: The authors declare no conflict of interest. 


\section{References}

1. Barthlott, W.; Neinhuis, C. Purity of the sacred lotus, or escape from contamination in biological surfaces. Planta 1997, 202, 1-8. [CrossRef]

2. Nørgaard, T.; Dacke, M. Fog-basking behaviour and water collection efficiency in Namib Desert Darkling beetles. Front. Zool. 2010, 7, 23. [CrossRef]

3. Lauder, G.V.; Wainwright, D.K.; Domel, A.G.; Weaver, J.C.; Wen, L.; Bertoldi, K. Structure, biomimetics, and fluid dynamics of fish skin surfaces. Phys. Rev. Fluids 2016, 1, 1-18. [CrossRef]

4. Uesugi, K.; Mayama, H.; Morishima, K. Proposal of a water-repellency model of water strider and its verification by considering directly measured strider leg-rowing force. J. Photopolym. Sci. Technol. 2020, 33, 185-192. [CrossRef]

5. Uesugi, K. Water-repellency model of the water strider, Aquarius paludum paludum, by the curved structure of leg micro-hairs. J. Photopolym. Sci. Technol. 2021, 34, 393-399. [CrossRef]

6. Bernhard, C.G. Structural and functional adaptation in a visual system. Endeavour 1967, 26, 79-84.

7. Wilson, S.J.; Hutley, M.C. The optical properties of "moth eye" antireflection surfaces. Opt. Acta: Int. J. Opt. 1982, 29, 993-1009. [CrossRef]

8. Watson, G.S.; Myhra, S.; Cribb, B.W.; Watson, J.A. Putative functions and functional efficiency of ordered cuticular nanoarrays on insect wings. Biophys. J. 2008, 94, 3352-3360. [CrossRef] [PubMed]

9. Peisker, H.; Gorb, S.N. Always on the bright side of life: Anti-adhesive properties of insect ommatidia grating. J. Exp. Biol. 2010, 213, 3457-3462. [CrossRef]

10. Ivanova, E.P.; Hasan, J.; Webb, H.K.; Truong, V.K.; Watson, G.S.; Watson, J.A.; Baulin, V.A.; Pogodin, S.; Wang, J.Y.; Tobin, M.J.; et al. Natural bactericidal surfaces: Mechanical rupture of Pseudomonas aeruginosa cells by cicada wings. Small 2012, 8, $2489-2494$. [CrossRef] [PubMed]

11. Ivanova, E.P.; Hasan, J.; Webb, H.K.; Gervinskas, G.; Juodkazis, S.; Truong, V.K.; Wu, A.H.F.; Lamb, R.N.; Baulin, V.A.; Watson, G.S.; et al. Bactericidal activity of black silicon. Nat. Commun. 2013, 4, 2838. [CrossRef]

12. Hausen, H. Comparative structure of the epidermis in polychaetes (Annelida). Hydrobiologia 2005, 535, 25-35. [CrossRef]

13. Holland, N.D.; Nealson, K.H. The fine structure of the echinoderm cuticle and the subcuticular bacteria of echinoderms. Acta Zool. 1978, 59, 169-185. [CrossRef]

14. Flammang, P.; Jangoux, M. Functional morphology of coronal and peristomeal podia in Sphaerechinus granularis (Echinodermata, Echinoida) Patrick. Zoomorphology 1993, 113, 47-60. [CrossRef]

15. Hirose, E.; Saito, Y.; Hashimoto, K.; Watanabe, H. Minute protrusions of the cuticle: Fine surface structures of the tunic in ascidians. J. Morphol. 1990, 204, 67-73. [CrossRef]

16. Hirose, E.; Lambert, G.; Kusakabe, T.; Nishikawa, T. Tunic cuticular protrusions in ascidians (Chordata, Tunicata): A perspective of their character-state distribution. Zool. Sci. 1997, 14, 683-689. [CrossRef]

17. Hirose, E.; Kimura, S.; Itoh, T.; Nishikawa, J. Tunic morphology and cellulosic components of pyrosomas, doliolids, and salps (Thaliacea, Urochordata). Biol. Bull. 1999, 196, 113-120. [CrossRef] [PubMed]

18. Hirose, E.; Uyeno, D. Histopathology of a mesoparasitic hatschekiid copepod in hospite: Does Mihbaicola sakamakii (Copepoda: Siphonostomatoida: Hatschekiidae) fast within the host fish tissue? Zool. Sci. 2014, 31, 546-552. [CrossRef]

19. Hirose, E.; Uyeno, D. Regional differentiation of the cuticular surface structure in the mesoparasitic copepod Cardiodectes shini (Siphonostomatoida: Pennellidae) on a pygmy goby. Invertebr. Surviv. J. 2016, 13, 134-139. [CrossRef]

20. Hirose, E.; Sakai, D.; Shibata, T.; Nishii, J.; Mayama, H.; Miyauchi, A.; Nishikawa, J. Does the tunic nipple array serve to camouflage diurnal salps? J. Mar. Biol. Assoc. UK 2015, 95, 1025-1031. [CrossRef]

21. Kakiuchida, H.; Sakai, D.; Nishikawa, J.; Hirose, E. Measurement of refractive indices of tunicates' tunics: Light reflection of the transparent integuments in an ascidian Rhopalaea sp. and a salp Thetys vagina. Zool. Lett. 2017, 3, 7. [CrossRef]

22. Hirose, E.; Mayama, H.; Miyauchi, A. Does the aquatic invertebrate nipple array prevent bubble adhesion? An experiment using nanopillar sheets. Biol. Lett. 2013, 9, 20130552. [CrossRef]

23. Ballarin, L.; Franchi, N.; Gasparini, F.; Caicci, F.; Miyauchi, A.; Hirose, E. Suppression of cell-spreading and phagocytic activity on nano-pillared surface: In vitro experiment using hemocytes of the colonial ascidian Botryllus schlosseri. Invertebr. Surviv. J. 2015, $12,82-88$

24. Hirose, E.; Sensui, N. Does a nano-scale nipple array (moth-eye structure) suppress the settlement of ascidian larvae? J. Mar. Biol. Assoc. UK 2019, 99, 1393-1397. [CrossRef]

25. Nagayama, K. Biomechanical analysis of the mechanical environment of the cell nucleus in serum starvation-induced vascular smooth muscle cell differentiation. J. Biomech. Sci. Eng. 2019, 14, 19-00364. [CrossRef]

26. Terzaghi, K.; Peck, R.B.; Mesri, G. Soil Mechanics in Engineering Practice, 3rd ed.; John Wiley \& Sons: Hoboken, NJ, USA, 1996; ISBN 978-0-471-08658-1.

27. Murray, H.H. Chapter 2 Structure and composition of the clay minerals and their physical and chemical properties. In Applied Clay Mineralogy; Murray, H.H., Ed.; Elsevier: Amsterdam, The Netherlands, 2006; Volume 2, pp. 7-31. ISBN 9780444517012.

28. Borges Cabrera, M.; Satomi, T.; Takahashi, H. Temperature: A key parameter on soil content reduction simulation in recycled asphalt aggregate. J. Clean. Prod. 2020, 261, 121236. [CrossRef]

29. Zhang, W.; Stack, A.G.; Chen, Y. Interaction force measurement between E. coli cells and nanoparticles immobilized surfaces by using AFM. Colloids Surf. B Biointerfaces 2011, 82, 316-324. [CrossRef] [PubMed] 
30. Spalding, A.; Shanks, K.; Bennie, J.; Potter, U.; Ffrench-Constant, R. Optical modelling and phylogenetic analysis provide in butterflies and moths. Insects 2019, 10, 262. [CrossRef] [PubMed]

31. Blagodatski, A.; Sergeev, A.; Kryuchkov, M.; Lopatina, Y.; Katanaev, V.L. Diverse set of Turing nanopatterns coat corneae across insect lineages. Proc. Natl. Acad. Sci. USA 2015, 112, 10750-10755. [CrossRef]

32. Kryuchkov, M.; Bilousov, O.; Lehmann, J.; Fiebig, M.; Katanaev, V.L. Reverse and forward engineering of Drosophila corneal nanocoatings. Nature 2020, 585, 383-389. [CrossRef] [PubMed]

33. Oeffner, J.; Lauder, G.V. The hydrodynamic function of shark skin and two biomimetic applications. J. Exp. Biol. 2012, 215, 785-795. [CrossRef] [PubMed]

34. Mihm, J.W.; Banta, W.C.; Loeb, G.I. Effects of adsorbed organic and primary fouling films on bryozoan settlement. J. Exp. Mar. Biol. Ecol. 1981, 54, 167-179. [CrossRef]

35. Flemming, H.C. Biofouling in water systems-Cases, causes and countermeasures. Appl. Microbiol. Biotechnol. 2002, 59, 629-640. [CrossRef]

36. Hirose, E.; Sensui, N. Substrate selection of ascidian larva: Wettability and nano-structures. J. Mar. Sci. Eng. 2021, 9, 634. [CrossRef] 